\title{
Information-cybernetic approach to computer learning of a foreign language
}

\author{
Liliya Polyakova, ${ }^{1, *}$, Yulia Yuzhakova $^{1}$, and Ludmila Antropova ${ }^{1}$ \\ ${ }^{1}$ Nosov Magnitogorsk State Technical University, 455000, 38 Lenin Ave, Magnitogorsk, Russia
}

\begin{abstract}
The present paper proves the important role of information and cybernetic approach in computer learning in the example of author's program for testing knowledge and skills of learners. The authors believe that "Test Your English" as an effective and universal way of improving the methodology of teaching a foreign language at school and University.
\end{abstract}

\section{Introduction}

Nowadays educational institutions are searching ways for effective foreign language teaching and learning. One of them is training school and university students with the help of computer technology. The methodology of computer foreign language training is based both on individualized and information-cybernetic approaches.

From the point of view of the information-cybernetic approach, the learning process is viewed as a process of obtaining, transforming, and storing educational information. Such a system consists of three main elements-subsystems, interacting with one another: the teacher, the student and the means of computer technology. The information approach to the training content planning allows us to find out the limits of each student's academic workload in the classroom where they work under the guidance of a teacher or with the help of computer technology means, as well as when doing unsupervised activities at home [1].

Information-cybernetic approach, on which computer technology as a means of teaching is based, makes training an extremely individualized process which is viewed as students' work with the information presented on the display screen.

Computerized training is a rational system of function distribution between a teacher and a computer in the process of students' studying and consolidating new knowledge and skills. The effectiveness of computer training is achieved due to the fact that it provides the opportunity to organize a dialogue with the learner: to present educational material, to ask questions, to respond promptly to answers, to monitor the correctness of sums and answers, etc. Computer technologies have allowed building the educational process with the account of the students' abilities, i.e. applying an individual approach to the training.

\section{Research Methods}

* Corresponding author: lilitmgn@mail.ru 
From a methodical point of view, one of the problematic aspects of computer foreign language training on the basis of information-cybernetic and individualized approaches is the correct application of electronic didactic courses. We have developed a trainingcontrolling computer course "Test your English", designed to monitor the knowledge and skills of students studying according to the "English Language" training program. This ecourse consists of two applications: a software shell that allows you to create test files, and the executive module. The program includes multimedia elements: you can insert audio texts and videos into the tests. The main program has a friendly graphical interface, designed to make testing an interesting activity.

In our opinion, after the final stage of approbation and introduction into the school and university didactic process, this program can be effectively applied in the work with different groups of students both in terms of knowledge and age. It can be used at home for unsupervised students' work, as well as at English classes at schools and at higher educational institutions in practical English grammar classes. The use of the program significantly facilitates the control of students' knowledge in order to identify and eliminate gaps, brings diversity in the teaching methodology, introduces modern technical training means, it can partially or completely eliminate the psychological barrier between the tested and testing persons.

All the tasks of the test (and their sub-tasks) are divided into four groups, listed below:

1. The tasks that verify compliance with the requirements of the educational standard (hereinafter referred to as the "Standard" group);

2. The tasks that verify the compliance of students' knowledge level with requirements that go beyond the educational standard ("Supplementary Material");

3. The tasks testing the understanding of the content of the work considered in the test ("Understanding the content");

4. The tasks that check the formation of the lexical and grammatical skills of students.

One of the main parts of the didactic computer complex "Test Your English" is the algorithm for analyzing the trainee's answers in the modes of doing exercises and tests. The computer compares the received answer with the reference in such a way that each time the learner's answer is compared with the correct (or incorrect) answer having been put in the computer database.

It is not possible to compile a database containing all the possible sentences of the language being studied. The task of finding the correct answer can partially be solved with the method of determining the correct answer by keywords. The executable program searches for certain words (or ascertains the fact of their absence) in the answer of the learner, defines the order in which they follow, and on this basis determines the correctness of the answer.

\section{Results and Discussion}

In the program "Test Your English", we tried to implement an algorithm for recognizing the answer given by the learner in no particular format. Each correct answer in a certain format is stored right after the question in the exercises or test file. The reference answers are divided into the blocks of three types:

1. Words that cannot be omitted or replaced by other words;

2. Words (or a group of words) that can only be replaced by other words or phrases equivalent in meaning;

3. Words or phrases that can be simultaneously replaced or omitted in the answer.

The work of the algorithm is based on the recognition of the blocks described above in the reference answer, their deployment to complete syntactic constructions, and their 
further comparison with the answer of the learner. Based on the above mentioned scheme, the answer like "He said he would come to Ann at $8 o^{\prime}$ clock" can be divided into the following blocks: [He, Peter $]$ - [said, told me $]$ - [that $]$ - [he, Tom $]$ - [would come to $]$ - [Ann, Ann's, Ann's house, Ann's apartment, Ann's flat $]$ - [at $]$ - [8, eight $]$ - [o'clock (in the morning, in the afternoon), p.m., a.m.].

Programmatically this scheme can be conditionally written as follows. The words or phrases of the first group are written in the form in which they should be presented. Words or phrases of the second group are placed with all possible equivalents in square brackets and separated by a slash, for example [he / Peter]. Words or phrases belonging to the third group are also placed in square brackets and separated by a slash, but immediately after the opening bracket the ${ }^{\prime * 1}$ character is placed indicating the program that this block can be omitted without any distortion of the general meaning of the sentence. Therefore, the whole answer can be presented in the following form:

[he / Peter $][$ said / told me $][* /$ that $][$ he / Tom $]$ would come to

[Ann / Ann's [house / flat / apartment] at [8 / eight $]$ [o'clock

$[* /$ in the [morning / evening] / p.m. / a.m. $]$

It can be seen from this sequence that one sentence with artificially inserted rules of recording the reference answer can comprise all 800 possible variants of the correct answer.

The primary information about each student's test results collected in the fixing test results matrix is provided by the program "Test Your English" after the appropriate processing of data in a single 100-point scale on the whole test and on each of the eight subtests separately. The transfer of primary information into numerical one is carried out on the basis of taking into account the weights of the primary information points contained in the fixing the test results matrix. This algorithm of transferring primary information into a numerical one makes it possible to uniquely match the activities of any student number, thereby realizing the measurement procedure. However, the obtained numerical data is not an assessment of the results of the students.

For evaluation, a criterion is needed that would allow us to make a qualitative judgment about the numerical values obtained. Within the framework of this test we used the "Standardized Scale of Assessment" with the following evaluation criteria:

- from 0 to 64 points - "poor";

- from 65 to 76 points - "satisfactory";

- from 77 to 91 points - "good";

- from 92 to 100 points - "excellent."

Approbation of the program "Test Your English" took place at the school-gymnasium No. 18 in Magnitogorsk, Russia in 2018. 20 students took part in the experiment: 10 people in the control group and 10 in the experimental group. Both groups used one and the same textbook, but in the experimental group, the training was based on computer-based testing, and in the control group, it was based on the method of non-computer training. Both groups studied English for the first year and used the textbook by V.P. Kuzovlev «English 5». The results of the assessment testing are given in Table 1.

The analysis of preliminary testing showed that the level of knowledge of the students of the experimental and control groups is approximately the same.

After the end of the experimental work, we conducted the final testing, the results of which are given in Table 2. In the control group, four people showed poor results as the three of them received satisfactory grades, and one student failed to do the assignment.

Thus, we see that the students in the experimental group showed better results than the students in the control group.

Table 1. Test results before the start of the experiment. 


\begin{tabular}{|c|c|c|}
\hline $\begin{array}{c}\text { Evaluation } \\
\text { (standardized scale) }\end{array}$ & $\begin{array}{c}\text { Experimental } \\
\text { Group }\end{array}$ & $\begin{array}{c}\text { Control } \\
\text { Group }\end{array}$ \\
\hline $\mathbf{1}$ & $\mathbf{2}$ & $\mathbf{3}$ \\
\hline "Excellent" & 3 & 3 \\
"Good" & 4 & 5 \\
"Satisfactorily" & 3 & 2 \\
"Poor" & 1 & 1 \\
\hline Average Score & 3,7 & 3,8 \\
\hline
\end{tabular}

Table 2. Test results at the end of the experiment.

\begin{tabular}{|c|c|c|}
\hline $\begin{array}{c}\text { Evaluation } \\
\text { (standardized scale) }\end{array}$ & $\begin{array}{c}\text { Experimental } \\
\text { Group }\end{array}$ & $\begin{array}{c}\text { Control } \\
\text { Group }\end{array}$ \\
\hline $\mathbf{1}$ & $\mathbf{2}$ & $\mathbf{3}$ \\
\hline "Excellent" & 7 & 3 \\
"Good" & 3 & 3 \\
"Satisfactorily" & - & 3 \\
"Poor" & - & 1 \\
\hline Average Score & 4,7 & 4,0 \\
\hline
\end{tabular}

\section{Conclusion}

So, as a result of the scientific and practical research, not only data was obtained that allowed to compare the level of knowledge of students trained by different methods, but also a standardized measuring tool was created that allows comparing the results of individual pupils as well as any groups of students. Familiarization of teachers with test results and studying the methodology of working with the program "Test Your English" will help to significantly optimize the process of computer foreign language learning at school and university.

\section{References}

1. A. V. Smirnov, Theory and methods of using the means of new information technologies in teaching physics. Abstract of diss. ... Candidate of Pedagogical Sciences (Moscow, 1996)

2. I. F. Harlamov, Pedagogy (YUrist, 1997) 